\title{
Programa de Pós-Graduação em Gerontologia da Universidade Federal de Santa Maria/RS
}

\section{Graduate Program Master's Degree in Gerontology of the Federal University of Santa Maria/RS}

\author{
Marco Aurelio de Figueiredo Acosta ${ }^{a}$ \\ a Doutor, Universidade Federal de Santa Maria - UFSM, RS, Brasil. <marco.acosta@bol.com.br>
}

\section{ARTICLE INFO}

\section{Article history}

Received: 17/06/2015

Accepted: 13/07/2015

\section{Correspondent Author}

Marco Aurelio de Figueiredo Acosta

Av. Roraima, 1000, Prédio 19

97105-900 Santa Maria, RS, Brasil

<marco.acosta@bol.com.br>

\section{(C) 2014 All rights reserved}

\section{Editors}

Alfredo Cataldo Neto

Irenio Gomes

\begin{abstract}
RESUMO
Objetivo: $\bigcirc$ presente artigo visa apresentar o Programa de Pós-Graduação Mestrado em Gerontologia da Universidade Federal de Santa Maria/RS. Descrição do caso: $O$ Mestrado em Gerontologia da UFSM iniciou suas atividades em 2014, vinculado ao Centro de Educação Física e Desportos da Universidade Federal de Santa Maria. Representou um passo adiante na caminhada do Programa Núcleo Integrado de Estudos e Apoio à Terceira ldade - NIEATI, que há três décadas desenvolve projetos e ações com as pessoas mais velhas. Sua estrutura contempla duas linhas de pesquisa, e são necessários 25 créditos para conclusão do curso. Situado na grande área interdisciplinar, abarca várias profissões e diferentes universidades. Conclusões: $\bigcirc$ Mestrado em Gerontologia da UFSM se soma a outros de igual iniciativa em nosso país, e considera a trajetória com as questões do envelhecimento da UFSM.
\end{abstract}

DESCRITORES: Pós-graduação; Gerontologia; Universidade.

\begin{abstract}
Goal: This article aims to present the Graduate Program Master's Degree in Gerontology of the Federal University of Santa Maria/RS. Description of the case. The Masters in Gerontology UFSM began operations in 2014, linked to the Physical Education Sports Center and Sports Centers the Federal University of Santa Maria. It represented a step forward in the journey of the Program Integrated of Studies and Support for the Elderly - NIEATI, that for three decades develops projects and actions with older people. Its structure includes two lines of research, and it takes $25 \mathrm{credits}$ to complete the course. Set in the interdisciplinary field, encompassing various professions and different universities. Conclusions. The Masters in Gerontology UFSM contributes to other initiatives in our country, and considers the trajectory with aging issues in UFSM.

KEYWORDS: Graduate; Gerontology; University.
\end{abstract}




\section{INTRODUÇÃO}

O presente relato de caso, visa apresentar o Programa de Pós-graduação em Gerontologia PPGERONTO do Centro de Educação Física e Desportos da Universidade Federal de Santa Maria, no Rio Grande do Sul. Esse Curso se situa dentro da grande área interdisciplinar, onde se encontram também todos os cursos semelhantes no estudo dos processos de envelhecimento.

Prado \& Sayd (2006) citando Groisman apontam para o surgimento de "tecnologias de diferenciação", que permitiram identificar o envelhecimento como um processo. São apresentados então os chamados saberes médicos no início do século XX, a instituição das aposentadorias e a criação de Asilos de velhos. Essas três tecnologias articuladas, fizeram emergir pela primeira vez, um esboço do que se chama hoje de conhecimento sobre o envelhecimento.

Nosso Mestrado iniciou suas atividades em agosto de 2014, surgindo como desdobramento de um trabalho de três décadas do Programa Núcleo Integrado de Estudos e Apoio à Terceira Idade - NIEATI, que articula projetos, ações e disciplinas em uma ação multidisciplinar. $\mathrm{O}$ relato que segue, apresenta um pouco dessa longa trajetória, permeada por vários atores sociais, e com uma marca incisiva de intervenção institucional.

Situado na grande área interdisciplinar, contempla duas linhas de pesquisa, com um corpo docente de 16 professores, e administrativamente localizado no Centro de Educação Física e Desportos. Além de se constituir como um curso interdisciplinar, também se caracteriza como interinstitucional, visto que duas docentes são de outras instituições.

O processo de sua estruturação, no entanto, remonta vários anos antes, ao menos 2010, quando percebemos a necessidade de investir na organização de um "Seminário de Pesquisa/Extensão", para complementar a dimensão extensionista, somando-se ao trabalho já estruturado a vários anos. Descrevo a seguir um pouco desse trabalho extensionista, que está na base do nosso Mestrado.

O Programa NIEATI foi criado em 1984, a partir da constatação do Professor José Francisco Silva Dias - Juca, de que o curso de Educação Física não formava profissionais para trabalhar com as populações mais velhas. Surgiu então o primeiro Projeto de Extensão, ainda em atividade, denominado "Grupos de Atividades Físicas para a Terceira Idade", levando exercícios físicos aos bairros. A partir desse projeto de extensão, outros foram surgindo, sendo também ampliado o leque de atuações, com a articulação com outros cursos da UFSM.
Historicamente situado após a primeira Conferência Mundial sobre o Envelhecimento, ocorrida em Viena em 1982, o Programa NIEATI busca "melhorar a autonomia dos movimentos físicos e intelectuais dos velhos, mantendo a dependência cada vez mais distante". Busca também gerar massa crítica relativa às questões do envelhecimento humano, formando recursos humanos através de um relacionamento pautado pela horizontalidade com os mais velhos. Hoje, tornado praticamente "corriqueiro" falar das questões demográficas e de visibilidade dessa parte da população, representava no início dos anos 80 , uma originalidade, ou até mesmo uma excentricidade, visto que nesse período, a Educação Física ainda estava fortemente ligada às questões do esporte.

Como diz Kofi Annan (2002) Secretário Geral das Nações Unidas na época da II Assembleia Mundial do Envelhecimento realizada em Madrid em 2002, referindo-se à I Assembleia, ocorrida em Viena:

"Passaram-se 20 anos desde que nossos antecessores se reuniram para aprovar o primeiro documento mundial que serviria de guia para as políticas sobre o envelhecimento. Desde então, o mundo mudou de tal maneira que é quase irreconhecível. Nosso objetivo fundamental é que não mudou: construir uma sociedade apropriada para todas as pessoas, de todas as idades."

De 1984 em diante, os projetos foram se multiplicando, partindo de ações do curso de Educação Física para gradativamente aglutinar em suas ações, outros cursos da UFSM, ainda no espectro da saúde. Surgem assim os projetos de dança, o coral, o trabalho nas Instituições de Longa Permanência para Idosos ILPI's, e um projeto diferenciado, o "Aluno Especial II", que possibilita a pessoas com mais de 55 anos se matricularem em até três disciplinas por semestre. Somando-se aos projetos outras dimensões foram abordadas, como a criação de disciplinas, a participação/ organização política nos Conselhos de Idosos, apoio à Prefeituras e entidades, entre outras ações.

Na esteira desse pensamento, surge em 1998, nosso maior evento, o ACAMPAVIDA, no qual durante dois dias, os mais velhos têm a oportunidade de desfrutar do conhecimento gerado no meio acadêmico, além de estabelecerem relacionamentos com outras pessoas da mesma geração. As atividades são desenvolvidas no Centro de Educação Física e Desportos e no Centro de Eventos da UFSM, contando com uma programação que contempla, além das oficinas dos cursos, uma Mostra Artística, onde os mais velhos apresentam seus números de dança e coreografias.

Os cursos envolvidos no ACAMPAVIDA são: Educação Física, Fisioterapia, Medicina, Terapia Ocupacional, Fonoaudiologia, PET - Saúde, Serviço 
Social, Odontologia - PET, Psicologia, Direito, Enfermagem - PET, Nutrição, Zootecnia - PET, Agronomia - PET. Além da UFSM, contamos com a participação efetiva do Centro Universitário Franciscano - UNIFRA e da Faculdade Integrada de Santa Maria - FISMA. Pelos cursos citados se percebe a capacidade de aglutinação multidisciplinar gerada pelo evento, o que possibilitou imaginarmos o passo adiante do Mestrado. Interessante registar que esse evento, realizado anualmente por 16 vezes, apresenta uma média de púbico de 1044 idosos.

A partir de 2010, criamos o "Seminário de Pesquisa/Extensão sobre Terceira Idade/Envelhecimento" realizado em cinco edições anuais consecutivamente, contemplando palestras e apresentações de trabalhos. Nessa curta trajetória, trouxemos palestrantes renomados de nosso estado, para contribuir com a formação de massa crítica em gerontologia.

Então, como desdobramento desse trabalho diversificado de 30 anos, nosso Projeto de Mestrado foi encaminhado na janela do Aplicativo para Cursos Novos - APCN de 2013. Porém devido a coincidência com a avaliação trienal da Coordenadoria de aperfeiçoamento de Pessoal do Nível Superior - CAPES, houve um atraso na resposta, que chegou apenas no final de dezembro daquele ano. Reunido, o grupo de docentes discutiu sobre a possibilidade de abertura em março ou agosto do ano seguinte e, considerando as questões óbvias de tempo, além de ouvir a experiência de colegas já participantes em outros programas, sobre as dificuldades de se organizar bancas para o início do ano, decidiu-se pelo início no segundo semestre de 2014.

\section{RELATO DO CASO}

Creio que quando vamos propor uma iniciativa, devemos adotar alguns princípios. Um deles é conhecer o que já existe sobre, e outro princípio, é conhecer nossos parceiros de trabalho. $\mathrm{O}$ ponto que segue se refere ao primeiro princípio: como os outros programas se organizaram em área de concentração, linhas de pesquisa e disciplinas. Inicialmente foi feita uma busca nos endereços eletrônicos dos demais cursos. Inclusive, através dessa busca, foram identificados cursos que até então não se conhecia. Nesse primeiro momento procedi listando áreas de concentração, linhas de pesquisa e disciplinas, quando por reincidência, alguns insights foram surgindo, como por exemplo, a necessidade de duas linhas de pesquisas vistas como "opostas" do ponto de vista epistemológico. Outro fato que surgiu nesse momento foi a origem diversa dos programas, tanto de faculdades, como de corpo docente.
O segundo princípio se refere à articulação docente dentro do nosso grupo, respeitando nossas características internas, e creio, possa ser dividida em três grupos. Alguns professores já eram conhecidos pela intervenção histórica no evento ACAMPAVIDA, principalmente na área da saúde. Um segundo grupo foi selecionado por ter cursado Mestrado e/ou Doutorado no já consolidado Programa Gerontologia Biomédica da PUCRS, e descobertos na forma da indicação direta. Finalmente, tínhamos um terceiro grupo de pessoas que trabalham com temáticas específicas, porém aplicadas à população mais velha, ou seja, como base empírica para coleta, embora não obrigatoriamente estudiosos dos processos de envelhecimento.

Do somatório desse "olhar para fora' e do "olhar para dentro”, surgiu nosso pré-projeto, fruto de reuniões semanais por vários meses e, na medida do possível, sólido na sua constituição. Durante esse percurso, algumas pessoas se somaram e outras ficaram na caminhada, mas registre-se que suas contribuições foram fundamentais para lograr o êxito.

Em nossa proposta apresentamos duas linhas de pesquisa, que inclusive, se fazem presentes em muitos outros cursos, representando uma pouco da divisão clássica entre as ciências biológicas e da vida de um lado, e as ciências sociais e humanas de outro. Nosso curso se situa na Área Básica: Saúde e Biológicas, e são necessários 25 créditos para integralização curricular, atingidos em disciplinas mas também em duas modalidade originais: coorientação de iniciação científica (1 Cr.) e estágios em laboratórios autorizados (2 Cr.). Além disso, tivemos a preocupação com um princípio básico da gerontologia que é o da multidisciplinaridade na compreensão do envelhecimento humano.

Abordando a natureza da interdisciplinaridade, Jeckel-Neto (2000) assim se refere:

"a natureza do processo de envelhecimento que permeia todos os aspectos da vida de uma pessoa, dos biológicos aos sociais, exige que a sua investigação também seja feita de maneira integrada, Aqueles que quiserem realizar investigações científicas sérias do processo de envelhecimento deverão buscar necessariamente o estudo em equipe. Esta equipe deve ser constituída de um grupo de pessoas das mais diversas origens profissionais, propiciando não apenas um estudo multidisciplinar, mas o grupo deverá estabelecer uma organização interna que o capacite a desenvolver uma interdisciplinaridade eficiente".

Partindo dessa perspectiva, organizamos a grade curricular com as seguintes disciplinas:

1. Fundamentos da Gerontologia (60 h)

2. Metodologia da Pesquisa (45 h)

3. Seminário de Projetos de Dissertação (45 h) 
4. Docência Orientada ( $30 \mathrm{~h})$

5. Elaboração da Dissertação

6. Aspectos Funcionais do Envelhecimento Humano $(60 \mathrm{~h})$

7. Bioética, Qualidade de Vida e o Cuidado ao Idoso em diferentes cenários (45 h)

8. Epidemiologia e Políticas Públicas do Envelhecimento Humano (45 h)

9. Metodologia do Ensino ( $45 \mathrm{~h}$ )

10. Gênero, Sexualidade e Envelhecimento (45 h)

11. Aspectos Sociais e Culturais do Envelhecimento Humano (45 h)

12. Alternativas de créditos:

a) Co-orientação de iniciação científica $(1 \mathrm{cr}$.)

b) Estágios em laboratórios autorizados $(2 \mathrm{cr}$.)

Netto (2002) citando Néri, comenta que a partir dos anos 90 do século passado surgem os primeiros cursos de pós-graduação:

“... em 1997 o de Gerontologia (Mestrado e Doutorado) na UNICAMP, em 1998 o de Gerontologia Social da PUC/SP (Mestrado) e em 2000 o de Gerontologia Biomédica da PUCRS (Mestrado e Doutorado), todos com caráter multidisciplinar."

Nossa área de concentração “...visa a capacitação de profissionais envolvidos nesta área, tanto da docência quanto da pesquisa. Através da interdisciplinaridade, objetiva a integração das diferentes profissões envolvidas no estudo do envelhecimento humano, com o intuito de reunir, sistematizar e consolidar conhecimentos e aplicações de princípios e práticas no campo da gerontologia". Denominamos assim nossas linhas de pesquisa: 1 - saúde, funcionalidade e qualidade de vida no envelhecimento humano; 2 - Sociedade e cultura no envelhecimento humano.

Entre o grupo de docentes, contamos com realidades bem diferentes, alguns iniciando sua trajetória de pesquisadores e orientadores, outros já com muitos anos de trabalho. Entre estes, três são Bolsistas Produtividade do CNPq.

De acordo com o parecer da CAPES, nosso exercício de pensar a interdisciplinaridade foi caracterizado no projeto por intermédio dos seguintes registros:

1. Variedades de áreas de formação do corpo docente;

2. Por disciplinas integradoras;

3. Por linhas de pesquisa abrangentes e focadas na colaboração entre as diferentes disciplinas;

4. Pelos projetos de pesquisa que, em sua maioria, permitem que o mesmo estudante experimente em seu projeto de dissertação as abordagens de dois ou mais pesquisadores de áreas distintas.

Quanto a produtividade do grupo que subscreveu a proposta, o parecer também foi muito positivo:
"A produção científica dos docentes nos últimos três anos é numerosa, bem distribuída e predominantemente difundida em veículos de boa qualidade. O índice de produtividade médio é elevado para os padrões da área e 100\% dos docentes permanentes têm índice de produtividade ótima. Os artigos nos estratos superiores do Qualis somam 69\% do total e relacionam-se predominantemente com a temática do curso"

Como anteriormente mencionado, a coincidência com a avaliação trienal fez com que houvesse uma demora na resposta da Comissão de avaliação, o que evidentemente aumentou exponencialmente a cada mês nossa expectativa. Com a chegada do parecer, e seu "tom" predominantemente positivo, geraram uma sensação de dever cumprido.

Uma característica presente em nosso Curso é a presença de docentes de outras instituições, caracterizando também uma interinstitucionalidade. A Professora Evelise M. Berlezi é docente na Universidade Regional Noroeste do RS - UNIJUÍ. A Professora Giovana Z. Mazo é docente da Universidade Estadual de Santa Catarina - UDESC.

Além da presença dessas docentes de outras IES, outra característica do curso é a presença de vários centros de ensino da UFSM. Seis docentes são do Centro de Educação Física e Desportos CEFD, cinco docentes são do Centro de Ciências da Saúde - CCS, e três docentes são do Centro de Educação Superior da Região Norte do RS - CESNORS. Ainda dando conta de diversidades, contamos com várias profissões no grupo docente: seis são professores de educação física; duas são nutricionista, uma médica, um engenheiro civil, duas fisioterapeutas, duas enfermeiras, uma fonoaudióloga, e uma bióloga. Percebe-se ainda a falta de profissionais das humanidades, como sociologia, antropologia, filosofia, entre outras.

Dessa amálgama de instituições, centros de ensino, e profissões surgiu nosso Mestrado em Gerontologia, situado como já foi dito na concepção multidisciplinar do conhecimento. Netto \& Ponte (1996) referindo-se ao conhecimento em gerontologia situam sua compreensão:

"Visto simplesmente pelo prisma biofisiológico é desconhecer os problemas ambientais, sociais, culturais e econômicos que, seguramente, em maior ou menor extensão participam do processo do envelhecimento. Há que se ter uma visão global do envelhecimento enquanto processo, e dos idosos enquanto indivíduos".

Considerando estarmos no primeiro ano, falar de nossa trajetória ainda é incipiente, embora tenhamos todos como meta subir nosso conceito junto a CAPES e abrir o Curso de Doutorado. 


\section{CONCLUSÃO}

O surgimento do Mestrado em Gerontologia da UFSM representa mais um passo no trabalho com as questões do envelhecimento humano. $O$ compromisso em romper com a "conspiração do silêncio", como diria Beauvoir (1990) relativa a velhice, têm norteado nossas ações nesses 30 anos de história.

\section{REFERÊNCIAS}

Annan K. Plano de Ação Internacional para o Envelhecimento, 2002. Organização das Nações Unidas - ONU, Brasília.
Beauvoir S. A velhice. Rio de Janeiro: Nova Fronteira; 1970.

Jeckel-Neto E. Gerontologia: desafio para o século XXI. In: Jeckel-Neto E, Mânica da Cruz I, org. Aspectos biológicos e geriátricos do envelhecimento. Porto Alegre: Edipucrs; 2000.

Netto MP. O estudo da velhice no século XX: histórico, definição do campo e termos básicos. In: Freitas E et al., org. Tratado de geriatria e gerontologia. Rio de Janeiro: Guanabara Koogan; 2002.

Netto MP, Ponte JR. Envelhecimento: desafio na transição do século. In: Netto MP. Gerontologia. São Paulo: Atheneu; 1996.

Prado SD, Sayda JD. A gerontologia como campo do conhecimento científico: conceito, interesses e projeto político. Ciência \& Saúde coletiva. 2006;11(2). 